\title{
智慧课堂视角下的“线上线下”相融合的教学新模式研究 一以《外贸会计》为例
}

Study on the New Teaching Mode Integrating "Online and Offline" from the Perspective of Intelligent Classroom

- Take Foreign Trade Accounting as an Example

方瑛

Ying Fang

安徽国际商务职业学院财会金融学院

中国·安徽 合肥 231131

School of Accounting and Finance, Anhui In statute of International Business,

Hefei, Anhui, 231131, China

基金项目:安徽省教育厅教学研究项目 阶段性成果:《基于智慧课堂的高职线 上与线下教学模式研究一以《外贸会 计》为例》【2018jyxm0956 】; 安徽省教育 厅《外贸会计》大规模在线开放课程 (MOOC) 示范项目【2016mooc088】
【摘 要】随着智慧课堂的广泛应用, 慕课、云平台等线上教学平台逐步改变了传统的线 下教学课堂。论文以《外贸会计》课程为例,构建了智慧课堂视觉下的线上线下相融合的教 学新模式。

【Abstract】With the wide application of smart classrooms, online teaching platforms such as MOOC and cloud platforms have gradually changed the traditional offline teaching classroom. This paper takes Foreign Trade Accounting as an example to construct a new teaching mode of online and offline integration under the vision of smart classroom.

【关键词】智慧课堂; 线上线下; 教学新模式

【Keywords】smart classroom; online and offline; new teaching model

【DOI 】10.36012/sde.v1i3.492

\section{1 引言}

2019 年 4 月,在云南昆明召开的全国教育信息化工作会 议上,教育部副部长钟登华强调, 信息化是社会发展的大势所 趋, 是历史的必然。要深入推进实现“三全两高一大”的教育信 息化 2.0 的发展目标。目前在“大智移云”时代,大学教育也要 与时俱进。为此, 本文以《外贸会计》为例, 从传统教育专用资 源转变为智慧教育发散资源、从培养师生信息技术应用能力 转化为提升师生信息素养、从线上线下融合应用转变为智慧 创新发展入手，构建了智慧课堂视觉下的线上线下相融合的 教育教学新模式 ${ }^{[1]}$

\section{2 构建“线上线下”相融合的教学新模式}

《外贸会计》的智慧课堂, 可以实时通过互联网、云平台、
物联网、移动端等信息化教学方式来教学,相对于传统的线下 教育更加灵活多样，也更加能体现学生平时学习的状态和对 知识的掌握水平 ${ }^{[2]}$ 。

笔者构建了一个线上线下相融合的教学模式,并以《外贸 会计》出口货物增值税退税知识点为例, 实例运用了线上线下 相结合的教学新体验, 详见图 1 。

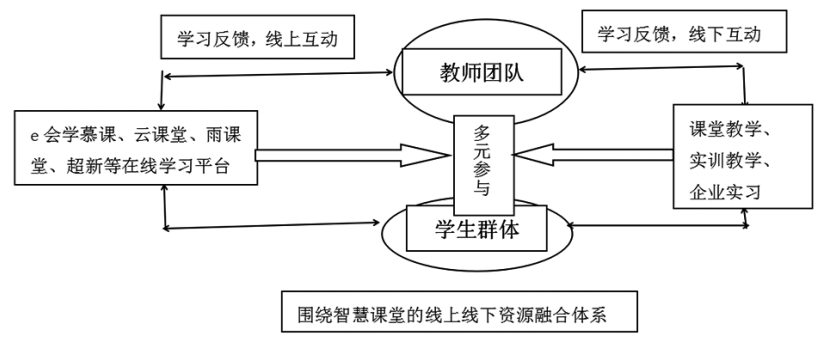

图 1 基于智慧课堂的线上线下相融合的教学新模式 
科学创新 Scientific Innovation

\section{1 课前预习(线上)}

课前, 教师通过云平台上传“外贸企业出口货物增值税退 (免) 税的计算”项目任务书, 学生通过云平台了解学习任务, 利用课余时间观看云平台上的视频资源，上网查阅相关资料， 带着任务进行学习, 还可以在平台上和小伙伴们发帖子讨论 互动, 初步掌握本知识点。教师也可以通过云平台教师端查 看每个学生的学习进程情况,监控学生学习记录。

\section{2 课中学习(线下)}

线上学习需要主动性。由于惰性, 很多学生只是为了完成 老师布置的任务而刷课, 并不能掌握所学的知识点, 具体到布 置的任务, 也可以让他人代劳, 所以仅靠线上教学的弊端也可 见一斑。这时候, “线下”面对面的教学显得尤为重要。

第一步,(线上)案例导人,分配任务。

可以在课前通过云平台推送给学生预习。例如, 某外贸企 业 2019 年 11 月出口货物取得销售收人 200 万美元，在国内 购进货物取得防伪税控开具的进项税额专用发票，注明金额 为 175 万元并通过主管税务机关认证。出口退税税率为 $13 \%$, 汇率为 $1: 7.1$ 。计算当期出口货物应退税额。

第二步,课堂(线下)学习理论。

平台上的在线视频和课件有本节课的学习目标和要求, 学生先预习, 再听老师详细讲解重点和难点, 掌握理论知识。 运用的公式如下：外贸企业出口货物增值税应退税额 $=$ 外贸 企业出口货物增值税退(免)税计税依据×出口货物退税率

这里面的计税依据是指在国内购买出口货物且取得增值 税专用发票的金额。

第三步,案例面对面解析。

根据学习进度引入公式,创造真实的工作情境, 小组成员 可以进行讨论,可以查阅资料,可以用抢答、头脑风暴等形式 激发学生互动的积极性。

解得, 应退税额 $=175 \times 13 \%=22.75$ (万元)

最后教师根据讨论情况进行点评, 通过案例法, 将枯燥的 会计知识和现实中的经济事件相结合, 使抽象的会计理论知
识变得生动活泼, 增加学生学习的兴趣。

第四步, 课后测试(线上)。

学习结束后, 教师通过云平台发布本节的测试题,进行学 习检验, 在线测试自动评分, 系统性地对测试结果适时分析, 教师可以实时考察学生对本节知识点的掌握情况, 可以对测 试结果不满意的学生退回重做, 并且在下次的课堂教学中对 错误率高的题目进行解析。随时调节教师的上课进度和课堂 重点难点, 有助于完善教和学的薄弱点, 使学生真正掌握并活 学活用知识。

\section{3 “线上线下”相融合的教学效果}

以 $\mathrm{e}$ 会学的慕课或者职教云的云课堂为平台实施“线上线 下”相融合的教学模式,一是利用智慧课堂时空的无限性, 让学 生利用移动终端完成学习和互动, 如课前任务导人、课中面对 面地答疑解析、课后在线测试教学成果。将学生从传统的被动 式的学习中引入到了主动学习的模式中, 培养学生的创新能 力。当然, 还要充分利用课堂教学来面对面地解决在线无法解 决的问题,无论互联网如何发达, 课堂教学(线下)仍具有重要 的现实意义, 它可对(线上)智慧课堂进行补充, 不可替代。上述 案例中, 通过线上和线下无缝对接, 让学生在智慧教育发散资 源 (线上)的课前和课后, 拓展了教学的时间和空间范围, 延展 了教学的深度和广度, 布置的任务又培养了学生的自主学习能 力和创新能力。在有限的时空中 (线下课堂教学) 快速掌握某一 小节的知识点,提升了师生信息素养, 对于培养会计专业具有 较强实践能力和创新能力的综合型技能人才具有现实意义。通 过大家的齐心协力,一定可以让教育信息化 2.0 变为现实。

\section{参考文献}

[1] 宋宝香,郑慧凌,祝嫦娥.基于 " 互联网 +" 的线上线下教学模 式探索——以市场调查与预测》课程为例 [J].中国教育信息化,2018 (18):60-62.

[2]赖俊丽. 智慧课堂教学模式在高职院校会计教学实践中的应 用[J].中外企业家,2018(36):160-161. 